\title{
Article \\ Skin Sensitization Evaluation of Carbon-Based Graphene Nanoplatelets
}

\author{
Sung-Hyun Kim $\mathbb{D}^{\mathbb{D}}$, So-Hye Hong, Jin Hee Lee, Dong Han Lee, Kikyung Jung, Jun-Young Yang, Hyo-Sook Shin, \\ JeongPyo Lee, Jayoung Jeong and Jae-Ho Oh *(i)
}

Division of Toxicological Research, National Institute of Food and Drug Safety Evaluation, Ministry of Food and Drug Safety, Osong, Cheongju 28159, Korea; tjdgus32@korea.kr (S.-H.K.); shhong99@korea.kr (S.-H.H.); tod98@korea.kr (J.H.L.); donghan04@korea.kr (D.H.L.); kikyung@korea.kr (K.J.); yangjy@korea.kr (J.-Y.Y.); aqua978@korea.kr (H.-S.S.); origene@korea.kr (J.L.); 0jjy@korea.kr (J.J.)

* Correspondence: mfdsnc@korea.kr; Tel.: +82-43-719-5102

Citation: Kim, S.-H.; Hong, S.-H.; Lee, J.H.; Lee, D.H.; Jung, K.; Yang,

J.-Y.; Shin, H.-S.; Lee, J.; Jeong, J.; Oh, J.-H. Skin Sensitization Evaluation of Carbon-Based Graphene Nanoplatelets. Toxics 2021, 9, 62. https://doi.org/10.3390/toxics 9030062

Academic Editor: Robyn L. Tanguay

Received: 23 February 2021

Accepted: 16 March 2021

Published: 17 March 2021

Publisher's Note: MDPI stays neutral with regard to jurisdictional claims in published maps and institutional affiliations.

Copyright: (C) 2021 by the authors. Licensee MDPI, Basel, Switzerland. This article is an open access article distributed under the terms and conditions of the Creative Commons Attribution (CC BY) license (https:/ / creativecommons.org/licenses/by/ $4.0 /)$.

\begin{abstract}
Graphene nanoplatelets (GNPs) are one of the major types of carbon based nanomaterials that have different industrial and biomedical applications. There is a risk of exposure to GNP material in individuals involved in their large-scale production and in individuals who use products containing GNPs. Determining the exact toxicity of GNP nanomaterials is a very important agenda. This research aimed to evaluate the skin sensitization potentials induced by GNPs using two types of alternative to animal testing. We analyzed the physicochemical characteristics of the test material by selecting a graphene nanomaterial with a nano-size on one side. Thereafter, we evaluated the skin sensitization effect using an in vitro and an in vivo alternative test method, respectively. As a result, we found that GNPs do not induce skin sensitization. In addition, it was observed that the administration of GNPs did not induce cytotoxicity and skin toxicity. This is the first report of skin sensitization as a result of GNPs obtained using alternative test methods. These results suggest that GNP materials do not cause skin sensitization, and these assays may be useful in evaluating the skin sensitization of some nanomaterials.
\end{abstract}

Keywords: skin sensitization; alternative to animal testing; KeratinoSens ${ }^{\mathrm{TM}}$; local lymph node assay (LLNA); nanomaterial; graphene

\section{Introduction}

Graphene nanoplatelets (GNPs), a two-dimensional monocrystalline layer form of carbon, are a major type of carbon-based nanomaterial which are used for various industrial and biomedical applications. Graphene has drawn attention across a vast field, such as in diverse devices or applied in batteries [1,2]. In recent years, as the types and production of GNPs have increased, concerns about toxicity caused by human exposure have increased exponentially. The major routes of exposure for nanomaterials are ingestion, inhalation and skin penetration in the workplace. Skin penetration of nanomaterials can induce lesions, contact allergy, local inflammation, and skin sensitization [3,4]. However, there are no studies on the toxicological database for GNP in skin sensitization which is the most easy exposure route in the workplace.

In addition, with the recent exponential increase in commercialization of nanomaterials for use in the cosmetic industry, etc., and the safety concerns associated with these, Nano safety evaluation has gained importance [5]. The focus on alternative methods in cosmetic testing is also increasing due to concerns regarding animal welfare and the 3Rs principle of replacement, reduction, and refinement [6,7]. However, as these guidelines are based on chemical substances, there is a need to develop alternative test methods that reflect the properties of nanomaterials.

The Organization for Economic Cooperation and Development (OECD) has suggested an adverse outcome pathway (AOP) leading to allergic contact dermatitis (ACD) starting 
with a molecular initiating event [8]. This shows that the related chemical and biological mechanisms can induce skin sensitization through a total of four key events. In general, the AOP of skin sensitization are classified by non-animal or animal testing methods. Animal-free test methods include the following assays: Direct Peptide Reactivity Assay (DPRA, key event 1), an in chemico assay, the antioxidant/electrophilic element (ARE) based Nuclear factor-erythroid 2-related factor 2 (Nrf2) luciferase test using a keratinocyte cell line (KeratinoSens ${ }^{\mathrm{TM}}$ assay, key event 2), and human cell line activation test (h-CLAT, key event 3) that simulates dendritic cells [9-11]. On the other hand, the key event 4 test method to confirm the activation of T cells is an alternative using experimental animals. Known as local lymph node assay (LLNA), this stage can be used to confirm activation of lymph nodes by sensitizers using enzyme-linked immunosorbent assay (ELISA) or flow cytometry (FCM) [12].

Evaluation of several nanomaterials' skin sensitization was recently performed and the applicability of these assays for testing nanomaterials was evaluated $[13,14]$. However, a lack of information regarding skin sensitization due to various nanomaterials, including GNPs, remains. Therefore, we evaluated the skin sensitization potential of GNPs using both alternative test methods, ARE-Nrf2 Luciferase KeratinoSens ${ }^{\mathrm{TM}}$ and LLNA: BrdUFCM assays.

\section{Materials and Methods}

\subsection{Graphene Nanoplatelets}

GNP (CAT\# 06-0225) materials were purchased from Strem Chemicals (Newburyport, MA, USA). Morphology of GNPs was observed by transmission electron microscopy (TEM; JEM-1200EX II, JEOL, Tokyo, Japan) and zeta potential was measured using a ZetasizerNano ZS instrument (Malvern Instruments, Malvern, UK) in different working solutions: Dulbecco's Modified Eagle's Medium (DMEM; GIBCO, Grand Island, NY, USA) containing $1 \%$ heat-inactivated fetal bovine serum (FBS; GIBCO) and N,N-Dimethylformamide (DMF; CASRN. 68-12-2, Sigma-Aldrich, St Louis, MO, USA) solution containing 3\% heatinactivated mice serum. Endotoxin were evaluated using an Endpoint Chromogenic Limulus Amoebocyte Lysate QCL-1000 (CAT\# 50-647U) assay (Cambrex, Walkersville, MD, USA). The endotoxin of GNP was measured according to the method and procedure provided by the kit manufacturer.

\subsection{Preparation of GNP Suspensions}

GNP suspensions were prepared by slightly modifying a formerly described method [15]. Briefly, GNP stock solutions were dispersed in distilled water (DW) and sonicated at $40 \mathrm{KHz}$ with $100 \mathrm{~W}$ output power for $30 \mathrm{~min}$ in a bath sonicator (Saehan-Sonic, Seoul, Korea). Thereafter, fresh DMEM media supplemented with $1 \%$ FBS was added to different working concentrations $(0.98-2000 \mu \mathrm{M})$. Since re-aggregation of GNP may be induced when DMEM culture medium is added, ultrasonic dispersion was performed for an additional $30 \mathrm{~min}$. In LLNA: 5-bromo2'-deoxyuridine (BrdU)-FCM assay, GNP stock solution was dispersed in DW and sonicated by the same procedure. Thereafter, serum $3 \%$ of the final volume was added to the dispersed stock solution and further dispersed for $30 \mathrm{~min}$. Finally, since re-aggregation of GNP may be induced when DMF solution (working concentration: 25,50, and $100 \% v / v$ ) is added, ultrasonic dispersion was performed for an additional $30 \mathrm{~min}$.

\subsection{KeratinoSens ${ }^{T M}$ Cell Culture}

A transgenic human keratinocyte cell line, with a stable insertion of the Luciferase reporter gene under control of the ARE-element KeratinoSens ${ }^{\mathrm{TM}}$ were provided by Givaudan Suisse SA (Vernier, Switzerland). KeratinoSens ${ }^{\mathrm{TM}}$ were cultured in DMEM media supplemented with 10\% FBS, $0.5 \mathrm{mg} / \mathrm{mL}$ Geneticin (Sigma-Aldrich). The cells were subcultured every $2-4$ days at $80-90 \%$ confluence for a maximum of 25 passages. Stabilized KeratinoSens $^{\mathrm{TM}}$ were seeded into 96 -well cell culture plate at a density of 10,000 cells/well. 
Cell cultured plates were incubated in a humidified atmosphere condition of $5 \% \mathrm{CO}_{2}$ at $37^{\circ} \mathrm{C}$.

\subsection{GNP Suspension Treatments and KeratinoSens ${ }^{T M}$ Assay Methods}

KeratinoSens ${ }^{\mathrm{TM}}$ were incubated overnight to reach approximately $80 \%$ confluency. The cells were washed once with pre-warmed pH 7.4 DPBS (Gibco), followed by the addition of dispersed GNPs suspension $(0.98-2000 \mu \mathrm{M})$, and the culture plates were then incubated for $48 \mathrm{~h}$. Positive control, cinnamic aldehyde (CASRN. 14371-10-9, Sigma-Aldrich), was tested in parallel (concentration: $4-64 \mu \mathrm{M}$ ). The viability of the treated KeratinoSens ${ }^{\mathrm{TM}}$ was measured using the thiazolyl blue tetrazolium bromide (3-(4,5-dimethylthiazo-2-yl)2,5-diphenyl-tetrazolium bromide assay reduction test (Promega, Madison, WI, USA). To exclude colorimetric interference from nanomaterials present in the cells, the supernatant was transferred into clear 96-well plates and the absorbance was measured at $570 \mathrm{~nm}$ with a microplate reader (Tecan, Männedorf, Switzerland). The cell viability (\%) was calculated based on the optical density of the vehicle control and blank control. Then, to measure the luciferase activity of GNP, we used the One-Glo ${ }^{\mathrm{TM}}$ Luciferase assay kit (Promega). The luciferase assay was conducted under the same conditions as the MTT assay. The luminescence intensity of each sample was measured using a multi-microplate reader (Synergy 2, BioTek, Winooski, VT, USA). Level of luciferase induction was calculated based on the luminescence values of the vehicle control and blank control.

\subsection{Pro-Inflammatory Cytokines Analysis of Supernatant}

In order to analyze inflammatory factors after exposure of GNPs to keratinocytes, the supernatant was separated and measured for inflammatory cytokines. The samples used were treated with a GNP solution for $48 \mathrm{~h}$ using the same procedure as for the KeratinoSens ${ }^{\mathrm{TM}}$ test, and then measured at concentrations of 500, 1000, and $2000 \mu \mathrm{M}$. The levels of inflammatory cytokines including interleukin (IL) $-1 \alpha$, IL-1 $\beta$, IL-8, and tumor necrosis factor- (TNF) - $\alpha$ were measured using commercially available ELISA kits. All ELISA Kits were purchased from R\&D systems (Duoset kit, Minneapolis, MN, USA) and measured according to the manufacture's procedure.

\subsection{Animals}

Female, seven weeks old, BALB/C mice (Specific Pathogen Free, SPF) were purchased from ORIENT BIO Inc (Seongnam, Korea). Mice were kept at an animal facility in the Ministry of Food and Drug Safety (MFDS), Korea and acclimated for at least six days before the experiments. Mice were housed in a relative humidity of $30-70 \%$ at $22 \pm 3{ }^{\circ} \mathrm{C}$. Food and water were supplied ad libitum. This experiment was approved by the Institutional Animal Care and Use Committee (IACUC) of MFDS (Approval number: MFDS-20-013c2; date: 23 April 2020).

\subsection{GNP Treatments and LLNA: BrdU-FCM Assay Methods}

On days 1, 2, and 3, dispersed GNPs suspension (working concentration: 25, 50, and $100 \% v / v$, respectively), vehicle control (DMF contained $3 \%$ mouse serum), and positive control ( $25 \%$ hexyl cinnamic aldehyde), were applied to the dorsal skin of each ear of the mouse at the same time-point (group per four). Acetone:olive oil (4:1 v/v, AOO) solvent was used to prepare the positive control based on the OECD test guideline 442B. GNP suspension was prepared fresh daily before application. On day 5 , all mice were intra-peritoneally (i.p) injected with $100 \mu \mathrm{L}$ of BrdU solution ( $20 \mathrm{mg} / \mathrm{mL}$ ). On day 6, mice were sacrificed and their auricular lymph nodes were isolated. Excised lymph nodes were mashed using a spatula to prepare lymph node cells (LNCs). LNCs were counted using a hemocytometer after staining with trypan-blue (Sigma). The quantitated LNCs $\left(1.5 \times 10^{6}\right.$ cells $\left./ \mathrm{mL}\right)$ were prepared for the LLNA: BrdU-FCM assay, according to the protocol provided in the BD Pharmingen ${ }^{\mathrm{TM}}$ FITC BrdU Flow Kit (BD Biosciences, San Jose, CA, USA). Viable LNCs were counted using a BD FACS Calibur ${ }^{\mathrm{TM}}$ flow cytometer (BD Biosciences) and a total of 
10,000 gated cells were analyzed, as previously described [16,17]. Stimulation index (SI) were calculated using the formula described in the OECD test guideline 442B [12]. If the SI was 2.7 or greater, the test materials were classified as sensitizers.

Stimulation Index $(S I)=\frac{\text { Number of BrdU }- \text { positive LNCs / mouse exposed to a test material }}{\text { Mean number of BrdU - positive LNCs in the vehicle control group }}$

\subsection{Statistical Analysis}

Data were analyzed with GraphPad Prism software ver. 5.0 (La Jolla, CA, USA) and presented as mean \pm standard error of the mean (SEM). Statistical analysis was performed by one-way ANOVA and each group was compared by post-hoc Turkey's pairwise comparisons. A result of $p$ value $<0.05$ was considered as statistically significant.

\section{Results}

\subsection{Physicochemical Characteristic of GNPs}

Physicochemical properties of GNPs are summarized in Table 1 and Figure 1. According to the information provided by the manufacturer, the graphene nanoplatelet aggregates used are submicron platelet aggregates less than 2 microns in diameter and several nanometers thick. Measurement of the zeta potential showed that GNPs were negatively-charged, with charge in distilled water (DW) and working solution. The results of Limulus Amoebocyte Lysate test showed that GNPs had endotoxin levels that were lower than the limit of detection $(0.1 \mathrm{U} / \mathrm{mL})$.

Table 1. Characteristics of graphene nanoplatelets.

\begin{tabular}{|c|c|c|}
\hline GNPs & In KeratinoSens ${ }^{\mathrm{TM}}$ & $\begin{array}{l}\text { In Local Lymph Node Assay } \\
\text { (LLNA): BrdU-FCM }\end{array}$ \\
\hline Diameter & \multicolumn{2}{|c|}{$<2$ microns, and a thickness of a few nanometers } \\
\hline Surface area $\left(\mathrm{m}^{2} / \mathrm{g}\right)$ & \multicolumn{2}{|c|}{300} \\
\hline \multicolumn{3}{|l|}{ Zeta potential $(\mathrm{mV})$} \\
\hline in DW & $-23.32 \pm 0.80$ & $-23.32 \pm 0.80$ \\
\hline in working solution * & $-27.17 \pm 0.94$ & $-24.60 \pm 0.26$ \\
\hline Molecular weight $(\mathrm{g} / \mathrm{mol})$ & \multicolumn{2}{|c|}{12.01} \\
\hline Carbon content $(\%)$ & \multicolumn{2}{|c|}{$>98$} \\
\hline Endotoxin $(\mathrm{EU} / \mathrm{mL})$ & \multicolumn{2}{|c|}{$<0.1$ (all samples) } \\
\hline
\end{tabular}

* Working solution (KeratinoSens ${ }^{\mathrm{TM}}$ ) was prepared with DW stock (1\%) + DMEM, containing 1\% FBS. Working solution (LLNA: BrdU-FCM) was prepared using DW stock (10\%) + DMF, containing 3\% mouse serum. Data are expressed as mean \pm SEM, $n=6$; GNPs = Graphene nanoplatelets, DW = distilled water, EU = endotoxin unit, DMEM = Dulbecco's Modified Eagle's Medium, FBS = Fetal bovine serum, DMF = N,N-Dimethylformamide.

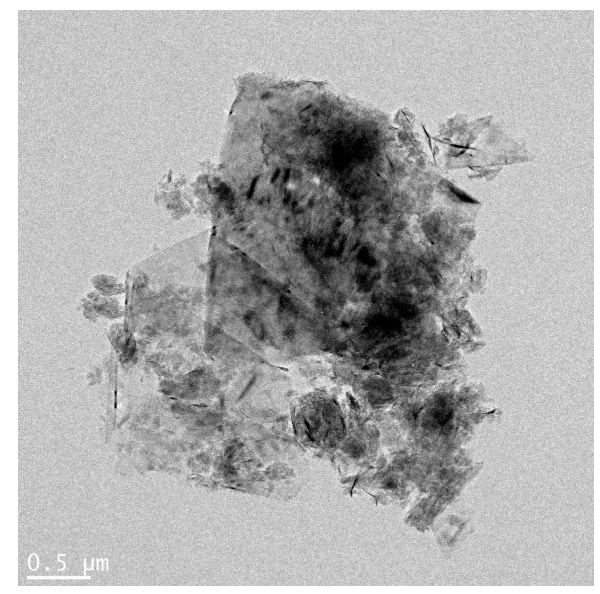

Figure 1. Agglomeration form of graphene nanoplatelets (bar $=0.5 \mu \mathrm{m})$. 


\subsection{Evaluation of GNPs in the KeratinoSens ${ }^{T M}$ Assay}

In order to apply the OECD Test Guideline 442D to graphene, a proficiency test using 10 proficiency substances suggested in the guideline was performed and results presented in Table 2. After completing the verification for a total of 10 substances, the GNPs were assessed for their skin sensitization potential using the KeratinoSens ${ }^{\mathrm{TM}}$ assay (Figure 2 and Table 3). GNPs did not induce the activity of the luciferase. The EC1.5 (interpolated concentration for a 1.5-fold luciferase induction) value for the GNPs was $>2000 \mu \mathrm{M}$, thus classifying it as a non-sensitizer. IC50 (concentration effecting a reduction of cellular viability by $50 \%$ ) values were found to be $>2000 \mu \mathrm{M}$ and cytotoxicity for GNPs was not found.

Table 2. Demonstrating technical proficiency of the KeratinoSens ${ }^{\mathrm{TM}}$ test method.

\begin{tabular}{|c|c|c|c|c|c|c|c|c|}
\hline \multirow{2}{*}{$\begin{array}{l}\text { Proficiency } \\
\text { Substances }\end{array}$} & \multirow{2}{*}{ CAS RN } & \multirow{2}{*}{$\begin{array}{l}\text { Physical } \\
\text { Form }\end{array}$} & \multirow{2}{*}{$\begin{array}{c}\text { In Vivo } \\
\text { Prediction }\end{array}$} & \multicolumn{2}{|c|}{ Reference Range * } & \multicolumn{3}{|c|}{ KeratinoSens $^{\mathrm{TM}}$ Assay } \\
\hline & & & & $\mathrm{EC}_{1.5}(\mu \mathrm{M})$ & $\mathrm{IC}_{50}(\mu \mathrm{M})$ & $\mathrm{EC}_{1.5}(\mu \mathrm{M})$ & $\mathrm{IC}_{50}(\mu \mathrm{M})$ & Results \\
\hline Isopropanol & $67-63-0$ & Liquid & $\begin{array}{c}\text { Non- } \\
\text { sensitizer }\end{array}$ & $>1000$ & $>1000$ & $>1000$ & $>1000$ & Negative \\
\hline $\begin{array}{l}\text { Salicylic } \\
\text { acid }\end{array}$ & $69-72-7$ & solid & $\begin{array}{c}\text { Non- } \\
\text { sensitizer }\end{array}$ & $>1000$ & $>1000$ & $>1000$ & $>1000$ & Negative \\
\hline Lactic acid & $50-21-5$ & Liquid & $\begin{array}{c}\text { Non- } \\
\text { sensitizer }\end{array}$ & $>1000$ & $>1000$ & $>1000$ & $>1000$ & Negative \\
\hline Glycerol & $56-81-5$ & Liquid & $\begin{array}{c}\text { Non- } \\
\text { sensitizer }\end{array}$ & $>1000$ & $>1000$ & $>1000$ & $>1000$ & Negative \\
\hline $\begin{array}{c}\text { Cinnamyl } \\
\text { alcohol }\end{array}$ & $104-54-1$ & solid & $\begin{array}{c}\text { Week- } \\
\text { sensitizer }\end{array}$ & $25-175$ & $>1000$ & 36.5 & $>1000$ & Positive \\
\hline $\begin{array}{c}\text { Ethylene } \\
\text { glycol } \\
\text { dimethacry- } \\
\text { late }\end{array}$ & $97-90-5$ & Liquid & $\begin{array}{c}\text { Week- } \\
\text { sensitizer }\end{array}$ & $5-125$ & $>500$ & 77.2 & 795.6 & Positive \\
\hline $\begin{array}{l}\text { 2-Mercapto } \\
\text { benzothia- } \\
\text { zole }\end{array}$ & $149-30-4$ & solid & $\begin{array}{l}\text { Moderate- } \\
\text { sensitizer }\end{array}$ & $25-250$ & $>500$ & 129.4 & 573.4 & Positive \\
\hline $\begin{array}{l}\text { Methyldibromo } \\
\text { glutaroni- } \\
\text { trile }\end{array}$ & 35691-65-7 & solid & $\begin{array}{l}\text { Strong- } \\
\text { sensitizer }\end{array}$ & $<20$ & 20-100 & 1.9 & 42.7 & Positive \\
\hline $\begin{array}{c}\text { 4- } \\
\text { Methylamino } \\
\text { phenol } \\
\text { sulfate }\end{array}$ & $55-55-0$ & solid & $\begin{array}{l}\text { Strong- } \\
\text { sensitizer }\end{array}$ & $<12.5$ & $20-200$ & 7.9 & 48.3 & Positive \\
\hline $\begin{array}{l}\text { 2,4-Dinitro- } \\
\text { chlorobenzene }\end{array}$ & $97-00-7$ & solid & $\begin{array}{l}\text { Extreme- } \\
\text { sensitizer }\end{array}$ & $<12.5$ & $5-20$ & 2.6 & 12.4 & Positive \\
\hline
\end{tabular}

${ }^{*}$ Information on the reference range was provided in OECD test guideline 442D.

Table 3. GNPs evaluated in KeratinoSens ${ }^{\mathrm{TM}}$ assay.

\begin{tabular}{|c|c|c|c|c|c|c|c|}
\hline \multirow{2}{*}{ NMs } & \multirow{2}{*}{ CAS RN } & \multirow{2}{*}{$\begin{array}{l}\text { Physical } \\
\text { Form }\end{array}$} & \multicolumn{5}{|c|}{ KeratinoSens ${ }^{\mathrm{TM}}$ Assay Results } \\
\hline & & & Imax & $\mathrm{EC}_{1.5}(\mu \mathrm{M})$ & Viability (\%) * & $\mathrm{IC}_{50}(\mu \mathrm{M})$ & Classification \\
\hline GNPs & $7782-42-5$ & Solid & 1.27 & $>2000$ & $>85$ & $>2000$ & Negative \\
\hline
\end{tabular}




\subsection{Evaluation of Pro-Inflammatory Cytokines in KeratinoSens ${ }^{T M}$ Cells}

Figure 3 shows the inflammatory factor analysis results of KeratinoSens ${ }^{\mathrm{TM}}$ cells treated with GNPs. GNPs showed a measurement result that did not exceed the range of the control group in the measured IL-1alpha, 8 and TNF-alpha cytokine results compared to the positive control group $(3 \mu \mathrm{M}), 2$,4-Dinitrochlorobenzene (DNCB). In the IL-1beta, statistical significance was observed at high concentration $(2000 \mu \mathrm{M})$, but this was below the detection limit of the kit, $1.95 \mathrm{pg} / \mathrm{mL}$.
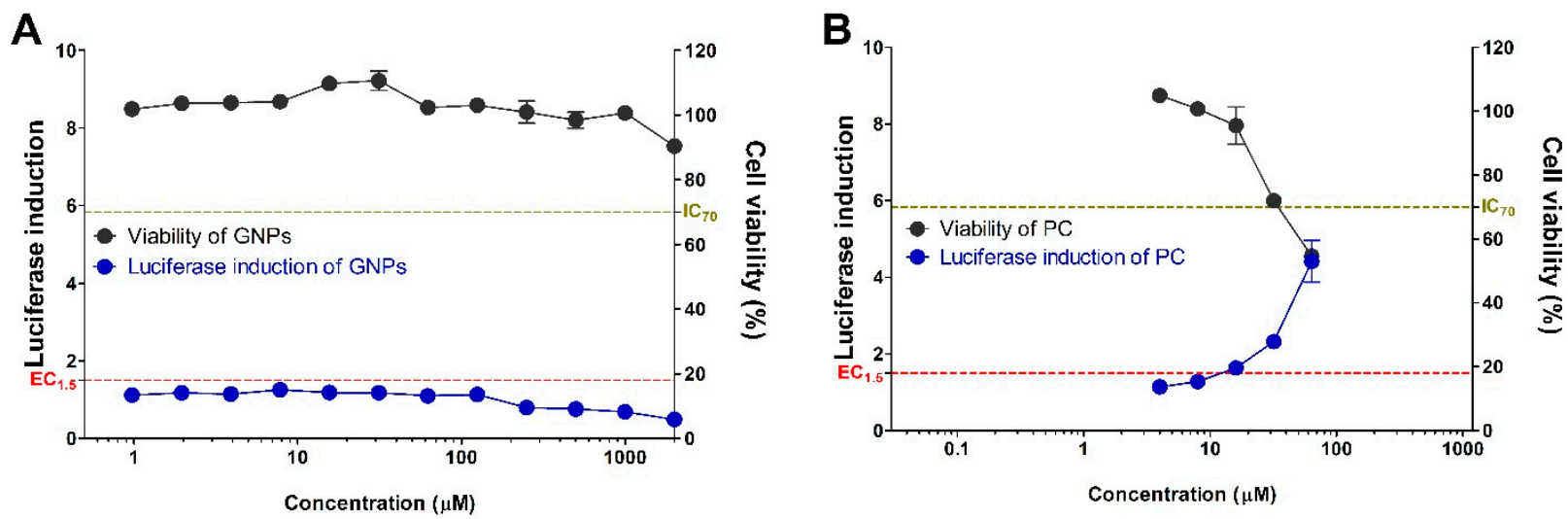

Figure 2. Induction of luciferase activity (blue line) and viability (black line) in the KeratinoSens ${ }^{\mathrm{TM}}$ assay. The cells were treated with the (A) graphene nanoplatelets (GNPs), and (B) positive control (cinnamic aldehyde, CAS number 14371-10-9). Data are expressed as mean $\pm \operatorname{SEM}(n=6)$. Positive control was tested in parallel $(4-64 \mu \mathrm{M})$.

A

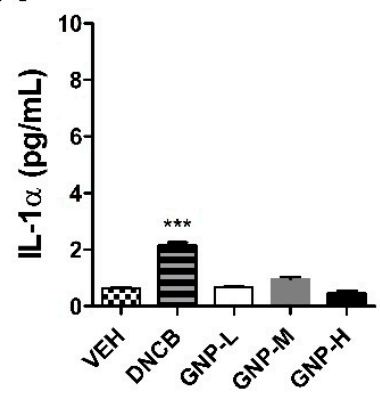

B

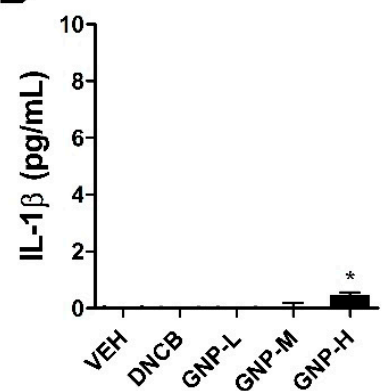

C

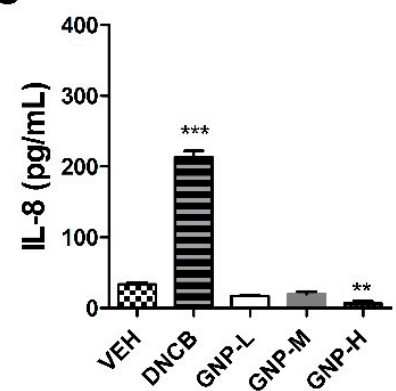

D

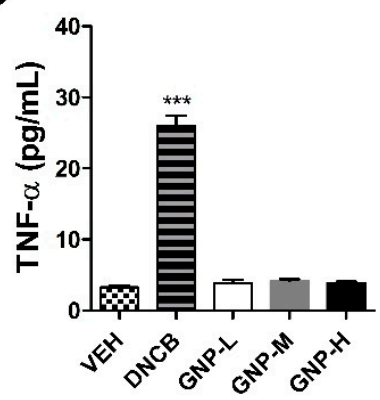

Figure 3. Expression of inflammatory cytokine in the KeratinoSens ${ }^{\mathrm{TM}}$ cells treated with the GNPs. The parameters were as follows: (A) IL-1alpha, (B) IL-1beta, (C) IL-8, and (D) tumor necrosis factor (TNF)-alpha (VEH = vehicle control, Low-dose $=500 \mu \mathrm{M}$, Mid-dose $=1000 \mu \mathrm{M}$, High-dose $=2000 \mu \mathrm{M})$. Data are expressed as mean \pm SEM values $(n=4)$. Each treatment group was compared with the vehicle control group to determine statistical significance. ${ }^{*} p<0.05 ;{ }^{* *} p<0.005 ;{ }^{* * *} p<0.0001$.

\subsection{Evaluation of GNPs in the LLNA: BrdU-FCM Assay}

GNPs were assessed for potential skin sensitization using the LLNA: BrdU-FCM, in vivo assay (Figure 4). No significant results were found at any concentration of GNPs except for the positive control (25\% hexyl cinnamic aldehyde) group for a total of six parameters: body weight, ear thickness and weight, lymph weight and lymph cell number, and stimulation index used for sensitization evaluation. Finally, the Stimulation Index (SI) value was found to be less than 2.7 , as calculated by flow cytometry, and was judged as a non-sensitizer through criteria of test guideline 442B. 
A

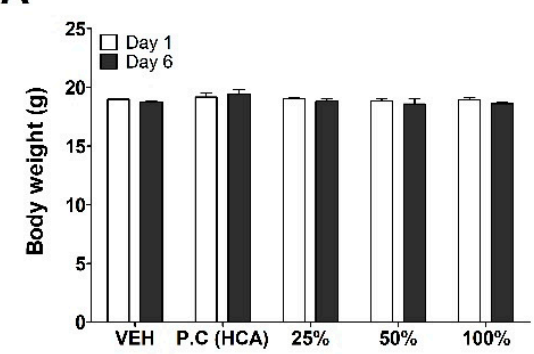

D

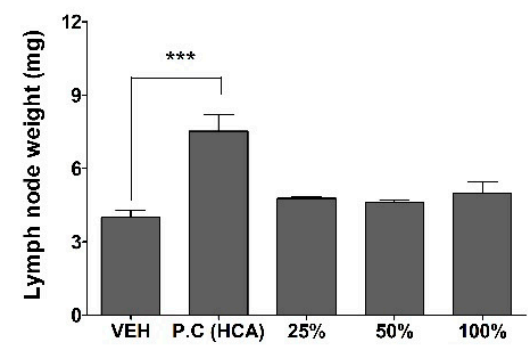

B

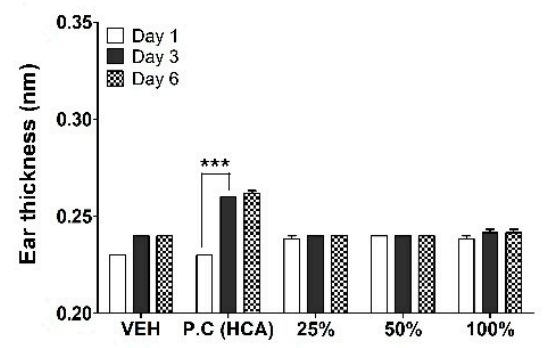

$\mathbf{E}$

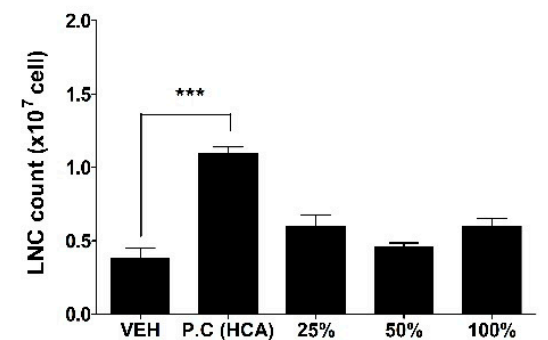

C

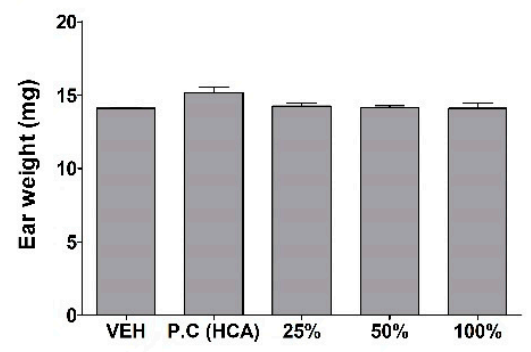

$\mathbf{F}$

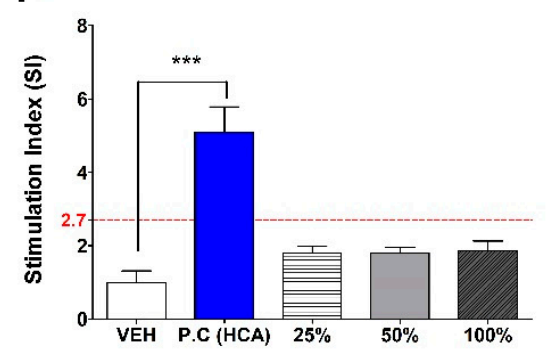

Figure 4. Results of GNPs skin sensitization potential in LLNA: BrdU-FCM. The evaluation parameters were as follows: (A) Body weight (g), (B) Ear thickness (mm), (C) Ear weight (mg), (D) Lymph node weight (mg), (E) Lymph node cell (LNC) count $\left(\times 10^{7}\right.$ cells), and (F) Stimulation Index (SI). Data are expressed as mean $\pm \operatorname{SEM}(n=4)$. Each treatment group was compared with the vehicle control group to determine statistical significance. ${ }^{* * *} p<0.0001$.

\section{Discussion}

GNPs, which have been called the 'dream material' have attracted attention for their extraordinary physicochemical properties, because of a wide range of promising applications in the biomedical and electronic fields [18]. Especially, GNP can be used to improve the properties of a wide range of polymeric materials, including thermoplastic and thermoset composites, natural or synthetic rubber, adhesives, thermoplastic elastomers, and paints and coatings because of their unique nanoscale size, shape, and material composition $[19,20]$. Since use is rapidly increasing in various industries during recent years, the safety of production workers (in workplaces) can be guaranteed through laws or regulations only when accurate identification of toxicity for the substance has been made.

Recently, with the growing emphasis on the 3Rs principle for testing, the use of animals in toxicity studies has become a major issue in the international community [6]. Alternative testing methods not involving the use of animals have been suggested by various countries and institutions, including the European Union Reference Laboratory for Alternatives to Animal Testing, the Interagency Coordinating Committee on the Validation of Alternative Methods, and the Japanese Center for the Validation of Alternative Methods. Studies are currently being carried out regarding this subject and the OECD has approved, enacted, and distributed guidelines for alternative test methods. The OECD TG 442 guidelines can be classified into four key events: key event 1: molecular initiation event, key event 2 and key event 3: cellular responses, and key event 4: organ-level responses based on AOP-inducing skin sensitization (Figure 5). These alternative test method guidelines can be evaluated on a chemical basis, but nanomaterials have the potential to act as happens due to a variety of physicochemical properties including nanoscale small sizes [21,22]. Therefore, in the current study, the test substances, GNPs, were evaluated for key event 2 and key event 4 by employing methods for confirming cellular responses and organ level responses in skin sensitization AOP.

Accuracy of the ARE-Nrf2 Luciferase KeratinoSens ${ }^{\mathrm{TM}}$ assay for identifying sensitizers was determined to be $77 \%(155 / 201)$ with a sensitivity of $78 \%(71 / 91)$. Laboratory-tolaboratory reproducibility has been reported to be approximately $85 \%[23,24]$. Although there are limitations on testing insoluble substances, some research has demonstrated that these substances can be evaluated $[25,26]$. The LLNA: BrdU-FCM test method employs the 
use of animals and previously reported studies have suggested the possibility of evaluating nanomaterials using this approach. For instance, Park et al. [13] conducted an LLNA test using titanium nanomaterials and reported that titanium does not induce skin sensitization.

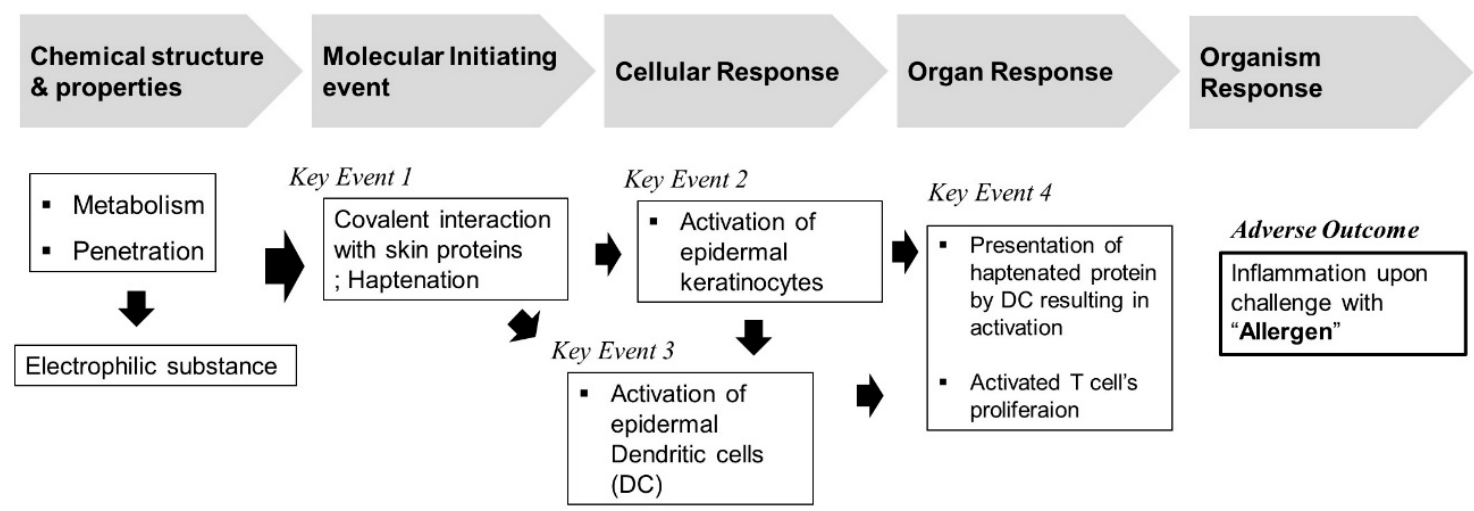

Figure 5. Overview of adverse outcome pathway (AOP) for skin sensitization.

In our study, GNPs are insoluble in most solvents and tend to easily form aggregates. Proper dispersion is very important for accurately predicting toxicity and hence homogeneous dispersion of the nanomaterials in solvents is important. In the current study, we used serum protein to improve the dispersion of GNPs in both the in vitro ARE-Nrf2 Luciferase KeratinoSens ${ }^{\mathrm{TM}}$ test and the in vivo LLNA: BrdU-FCM test. In the in vitro test, dispersion was induced by including FBS as a component in the medium. Meanwhile, mouse serum was used as a nanomaterial dispersant in the in vivo tests [27]. This was chosen based on previous reports that inactivated serum obtained from the same species reduces the amount of large aggregation and that there are no side effects caused by serum $[28,29]$.

In the current report, we describe for the first time sensitization results of GNPs using the ARE-Nrf2 Luciferase KeratinoSens ${ }^{\mathrm{TM}}$ and LLNA: BrdU-FCM test methods. In summary, the skin sensitization results for GNPs using the two alternative tests were negative. In our study, it was shown that the well-known sensitizer-induced inflammation indicator IL-1alpha was not induced [30,31]. Moreover, when judged considering all the results such as IL-1beta, IL-8 and TNF-alpha, which are cytokines related to acute inflammatory reactions, graphene does not appear to have an inflammatory effect on keratinocytes. The IL-1beta cytokine result is very small, but the significant increase in GNPs compared to the control may have been induced by inflammasome formation induced by intracellular incomplete phagocytosis depending on the type of substance [32]. In addition, this is related to the decrease in cell viability of GNPs at the highest concentration. DNCB, a sensitizer, is a completely soluble chemical, so it does not appear to induce IL-1beta through complete phagocytosis.

Until now, there is no research on skin sensitization of graphene, but there are cases of the evaluation of carbon-based nanomaterials. Although graphene and carbon nanotubes are completely different shape materials, they are nanomaterials that have the same element as carbon. Carbon nanotubes have been reported as non-sensitizing materials through the guinea pig sensitization test and the mouse lymph node test [33,34]. In our previous study, carbon nanotubes, evaluated skin sensitization using alternative studies in vitro and in vivo and did not induced sensitization [15].

\section{Conclusions}

We report the sensitization test results of GNPs using the in vitro and in vivo alternative test methods. We found that GNPs did not induce skin sensitization in both assays. Nano-graphene used as a product exists as various types because it attaches to functional groups or is manufactured in different sizes and layers. However, the current study reports only one type of graphene evaluation result. In summary, to secure the safety of commer- 
cialized GNP, it is suggested that additional data acquisition is necessary through more research. Furthermore, it is necessary to protect workers in the workplace and establish guidelines for skin sensitization specific to nanomaterials for use in various studies.

Author Contributions: Participated in the experimental design and data analysis: S.-H.K., J.H.L., and K.J.; conducted the in vitro experiments: S.-H.K., S.-H.H.; in vivo experiments: S.-H.K., D.H.L., and J.H.L., with help of J.-Y.Y., H.-S.S., J.L. and K.J.; writing—original draft preparation: S.-H.K. and S.-H.H.; project administration: J.J. and J.-H.O. All authors have read and agreed to the published version of the manuscript.

Funding: This work was supported by a grant (20181MFDS401) from the Ministry of Food and Drug Safety, Korea.

Institutional Review Board Statement: This study was approved by the Institutional Animal Care and Use Committee (IACUC) of Ministry of Food and Drug Safety (Approval number: MFDS-20013c2; date: 23 April 2020).

Informed Consent Statement: Not applicable.

Data Availability Statement: The original contributions presented in the study are included in the article, further inquiries can be directed to the corresponding authors.

Conflicts of Interest: The authors declare that they have no known competing financial interests or personal relationships that could have appeared to influence the work reported in this paper.

\section{References}

1. Chen, Y.; Zhang, B.; Liu, G.; Zhuang, X.; Kang, E.-T. Graphene and its derivatives: Switching ON and OFF. Chem. Soc. Rev. 2012, 41, 4688-4707. [CrossRef]

2. Wang, H.; Cui, L.-F.; Yang, Y.; Casalongue, H.S.; Robinson, J.T.; Liang, Y.; Cui, Y.; Dai, H. Mn3O4-Graphene Hybrid as a High-Capacity Anode Material for Lithium Ion Batteries. J. Am. Chem. Soc. 2010, 132, 13978-13980. [CrossRef]

3. Oberdörster, G.; Oberdörster, E.; Oberdörster, J. Nanotoxicology: An Emerging Discipline Evolving from Studies of Ultrafine Particles. Environ. Health Perspect. 2005, 113, 823-839. [CrossRef] [PubMed]

4. Maynard, A.D.; Kuempel, E.D. Airborne Nanostructured Particles and Occupational Health. J. Nanoparticle Res. 2005, 7, 587-614. [CrossRef]

5. Dréno, B.; Alexis, A.; Chuberre, B.; Marinovich, M. Safety of titanium dioxide nanoparticles in cosmetics. J. Eur. Acad. Dermatol. Venereol. 2019, 33, 34-46. [CrossRef] [PubMed]

6. Rusche, B. The 3Rs and animal welfare-Conflict or the way forward? ALTEX 2003, 20, 63-76. [PubMed]

7. Kaluzhny, Y.; Kandárová, H.; Hayden, P.; Kubilus, J.; D’Argembeau-Thornton, L.; Klausner, M. Development of the EpiOcular ${ }^{\mathrm{TM}}$ Eye Irritation Test for Hazard Identification and Labelling of Eye Irritating Chemicals in Response to the Requirements of the EU Cosmetics Directive and REACH Legislation. Altern. Lab. Anim. 2011, 39, 339-364. [CrossRef]

8. OECD. The Adverse Outcome Pathway for Skin Sensitisation Initiated by Covalent Binding to Proteins; OECD Series on Testing and Assessment, No. 168; OECD Publishing: Paris, France, 2014. [CrossRef]

9. OECD. Test No. 442C: In Chemico Skin Sensitization: Assays Addressing the Adverse Outcome Pathway Key Event on Covalent Binding to Proteins, OECD Guidelines for the Testing of Chemicals Section 4. 2020. Available online: https:/ /www.oecd-ilibrary. org/environment/test-no-442c-in-chemico-skin-sensitisation_9789264229709-en (accessed on 26 June 2020).

10. OECD. Test No. 442D: In Vitro Skin Sensitisation: ARE-Nrf2 Luciferase Test Method. Organisation for Economic Co-Operation and Development (OECD), Paris 10. 2018. Available online: https:/ /www.oecd-ilibrary.org/environment/test-no-442d-invitroskin-sensitisation_9789264229822-en (accessed on 25 June 2018).

11. OECD. Test No 442E: In Vitro Skin Sensitisation: In Vitro Skin Sensitisation Assays Addressing the Key Event on Ac-Tivation of Dendritic Cells on the Adverse Outcome Pathway for Skin Sensitisation. OECD Guidelines for the Testing of Chemicals, Section 4: 21. 2018. Available online: https://www.oecd-ilibrary.org/environment/test-no-442e-in-vitro-skin-sensitisation_9789264264 359-en (accessed on 25 June 2018).

12. OECD. Test No. 442B: Skin Sensitization: Local Lymph Node Assay: BrdU-Elisa or-Fcm. OECD Guidelines for the Testing of Chemicals, Section 4. 2018. Available online: https:/ / www.oecd-ilibrary.org/environment/test-no-442bskin-sensitization_9789 264090996-en (accessed on 25 June 2018).

13. Park, Y.-H.; Jeong, S.H.; Yi, S.M.; Choi, B.H.; Kim, Y.; Kim, I.; Kim, M.-K.; Son, S.W. Analysis for the potential of polystyrene and TiO2 nanoparticles to induce skin irritation, phototoxicity, and sensitization. Toxicol. In Vitr. 2011, 25, 1863-1869. [CrossRef]

14. Yoshioka, Y.; Kuroda, E.; Hirai, T.; Tsutsumi, Y.; Ishii, K.J. Allergic Responses Induced by the Immunomodulatory Effects of Nanomaterials upon Skin Exposure. Front. Immunol. 2017, 8, 169. [CrossRef]

15. Kim, S.; Lee, D.H.; Lee, J.H.; Yang, J.-Y.; Shin, H.-S.; Lee, J.; Jung, K.; Jeong, J.; Oh, J.-H.; Lee, J.K. Evaluation of the Skin Sensitization Potential of Carbon Nanotubes Using Alternative In Vitro and In Vivo Assays. Toxics 2020, 8, 122. [CrossRef] 
16. Jung, K.-M.; Bae, I.-H.; Kim, B.-H.; Kim, W.-K.; Chung, J.-H.; Park, Y.; Lim, K.-M. Comparison of flow cytometry and immunohistochemistry in non-radioisotopic murine lymph node assay using bromodeoxyuridine. Toxicol. Lett. 2010, 192, $229-237$. [CrossRef]

17. Ahn, I.; Kim, T.-S.; Jung, E.-S.; Yi, J.-S.; Jang, W.-H.; Jung, K.; Park, M.; Jung, M.-S.; Jeon, E.-Y.; Yeo, K.-U.; et al. Performance standard-based validation study for local lymph node assay: 5-bromo-2-deoxyuridine-flow cytometry method. Regul. Toxicol. Pharmacol. 2016, 80, 183-194. [CrossRef] [PubMed]

18. Brownson, D.A.C.; Banks, C.E. Graphene electrochemistry: An overview of potential applications. Analyst 2010, 135, 2768-2778. [CrossRef]

19. Zhang, Y.; Nayak, T.R.; Hong, H.; Cai, W. Graphene: A versatile nanoplatform for biomedical applications. Nanoscale 2012, 4, 3833-3842. [CrossRef]

20. Nasirzadeh, N.; Azari, M.R.; Rasoulzadeh, Y.; Mohammadian, Y. An assessment of the cytotoxic effects of graphene nanoparticles on the epithelial cells of the human lung. Toxicol. Ind. Health 2019, 35, 79-87. [CrossRef]

21. Dobrovolskaia, M.A.; McNeil, S.E. Immunological properties of engineered nanomaterials. Nat. Nanotechnol. 2007, 2, 469-478 [CrossRef] [PubMed]

22. Cho, W.-S.; Duffin, R.; Bradley, M.; Megson, I.L.; MacNee, W.; Howie, S.E.; Donaldson, $\mathrm{K} . \mathrm{NiO}$ and $\mathrm{Co}_{3} \mathrm{O}_{4}$ nanoparticles induce lung DTH-like responses and alveolar lipoproteinosis. Eur. Respir. J. 2011, 39, 546-557. [CrossRef] [PubMed]

23. Natsch, A.; Ryan, C.A.; Foertsch, L.; Emter, R.; Jaworska, J.; Gerberick, F.; Kern, P. A dataset on 145 chemicals tested in alternative assays for skin sensitization undergoing prevalidation. J. Appl. Toxicol. 2013, 33, 1337-1352. [CrossRef]

24. EURL-ECVAM. Recommendation on the KeratinoSens ${ }^{\mathrm{TM}}$ Assay for Skin Sensitisation Testing; JRC Scientific and Policy Reports. Publication Office of the European Union: Luxembourg, Germany, 2014. Available online: https:/ / ec.europa.eu/jrc/en/publication/eurscientific-and-technical-research-reports/eurlecvam-recommendation-keratinosenstm-assay-skin-sensitisation-testing (accessed on 22 October 2020).

25. Andres, E.; Sá-Rocha, V.M.; Barrichello, C.; Haupt, T.; Ellis, G.; Natsch, A. The sensitivity of the KeratinoSens ${ }^{\mathrm{TM}}$ assay to evaluate plant extracts: A pilot study. Toxicol. In Vitro 2013, 27, 1220-1225. [CrossRef]

26. Settivari, R.S.; Gehen, S.C.; Amado, R.A.; Visconti, N.R.; Boverhof, D.R.; Carney, E.W. Application of the KeratinoSens ${ }^{\mathrm{TM}}$ assay for assessing the skin sensitization potential of agrochemical active ingredients and formulations. Regul. Toxicol. Pharmacol. 2015, 72, 350-360. [CrossRef]

27. Bihari, P.; Vippola, M.; Schultes, S.; Praetner, M.; Khandoga, A.G.; A Reichel, C.; Coester, C.; Tuomi, T.; Rehberg, M.; Krombach, F. Optimized dispersion of nanoparticles for biological in vitro and in vivo studies. Part. Fibre Toxicol. 2008, 5, 14. [CrossRef] [PubMed]

28. Cho, W.-S.; Thielbeer, F.; Duffin, R.; Johansson, E.M.V.; Megson, I.L.; MacNee, W.; Bradley, M.; Donaldson, K. Surface functionalization affects the zeta potential, coronal stability and membranolytic activity of polymeric nanoparticles. Nanotoxicology 2013, 8, 202-211. [CrossRef] [PubMed]

29. Lee, S.; Hwang, S.-H.; Jeong, J.; Han, Y.; Kim, S.-H.; Lee, D.; Lee, H.-S.; Chung, S.-T.; Jeong, J.; Roh, C.; et al. Nickel oxide nanoparticles can recruit eosinophils in the lungs of rats by the direct release of intracellular eotaxin. Part. Fibre Toxicol. 2015, 13, 30. [CrossRef] [PubMed]

30. Coquette, A.; Berna, N.; VandenBosch, A.; Rosdy, M.; De Wever, B.; Poumay, Y. Analysis of interleukin- $1 \alpha($ IL- $1 \alpha)$ and interleukin8 (IL-8) expression and release in in vitro reconstructed human epidermis for the prediction of in vivo skin irritation and/or sensitization. Toxicol. In Vitr. 2003, 17, 311-321. [CrossRef]

31. Bezerra, S.F.; Rodrigues, B.D.S.; Da Silva, A.C.G.; De Ávila, R.I.; Brito, H.R.G.; Cintra, E.R.; Veloso, D.F.M.C.; Lima, E.M.; Valadares, M.C. Application of the adverse outcome pathway framework for investigating skin sensitization potential of nanomaterials using new approach methods. Contact Dermat. 2021, 84, 67-74. [CrossRef]

32. Van de Veerdonk, F.L.; Netea, M.G.; Dinarello, C.A.; Joosten, L.A. Inflammasome activation and IL-1 $\beta$ and IL-18 processing during infection. Trends Immunol. 2011, 32, 110-116. [CrossRef]

33. OECD. Multiwalled Carbon Nanotubes (MWCNT): Summary of the Dossier, Series on the Safety of Manufactured Nanomaterials No. 68. 2016. Available online: http:/ / www.oecd.org/officialdocuments/publicdisplaydocumentpdf $/$ ?cote $=\mathrm{env} / \mathrm{jm} / \mathrm{mono}(2016$ b)20\&doclanguage $=$ en (accessed on 30 May 2016).

34. OECD. Single Walled Carbon Nanotubes (SWCNTs): Summary of the Dossier, Series on the Safety of Manufactured Nanomaterials No. 70. 2016. Available online: http:/ / www.oecd.org/officialdocuments/publicdisplaydocumentpdf $/$ ? cote $=\mathrm{env} / \mathrm{jm} / \mathrm{mono}(2016$ a)22\&doclanguage $=$ en (accessed on 7 July 2016). 